\title{
Boiling Heat Transfer Enhancement Using Engineered Surfaces
}

\author{
Gurpyar Dhadda $^{1,2}$, Mohamed Hamed ${ }^{1,2}$, Philip Koshy ${ }^{2}$ \\ ${ }^{1}$ Thermal Processing Laboratory, McMaster University \\ 1280 Main Street, Hamilton, Canada \\ hamedm@mcmaster.ca \\ ${ }^{2}$ Department of Mechanical Engineering, McMaster University \\ 1280 Main Street, Hamilton, Canada
}

\begin{abstract}
The widespread use of boiling heat transfer in various applications is due to high heat transfer coefficients associated with the phase change from liquid to vapor. Boiling heat transfer coefficients can be further enhanced by modifying the surface conditions of the heated surface at which boiling occurs. The objective of this research is to fabricate textured surfaces with electrical discharge machining (EDM) and to investigate the enhancement in pool boiling heat transfer, concerning machining parameters. It was found that the boiling performance of the surface correlates with the EDM machining parameters with a significant enhancement in heat transfer.
\end{abstract}

Keywords: Pool boiling, Electrical discharge machining, Heat transfer enhancement.

\section{Introduction}

Surface engineering encompasses techniques related to the modification of the geometry of heat transfer surfaces at the macroscale, microscale or nanoscale level, or surface physicochemical properties by coatings. Various engineered surfaces have been proposed in the past to modify the surface conditions that include the geometrical shape and surface wettability (physical and chemical) and exploit them for application in boiling heat transfer enhancement. These include: (a) micro/nanostructured finned surfaces, tunnel or re-entrant cavities fabricated using polishing, mechanical deformation, rolling, knurling, milling, electrical discharge machining and sandblasting, (b) surface coating techniques using $\mathrm{Al}_{2} \mathrm{O}_{3}, \mathrm{TiO}_{2}$, $\mathrm{CuO}_{2}, \mathrm{Fe}_{2} \mathrm{O}_{3}$ nanoparticles or Polytetrafluoroethylene (PTFE), (c) MEMS/NEMS techniques by etching, and (d) porous mesh and foam attachments.

Electrical Discharge Machining (EDM) is a non-conventional machining technique where material is removed by rapidly recurring electrical discharges on the surface. Several studies have used EDM to texture surfaces for pool boiling enhancement in past, either as a primary manufacturing process or as a secondary process. Jones et al. [1] used EDM to prepare surfaces with different average surface roughness, $R a$, in the range of $1.08 \mu \mathrm{m}$ and $10 \mu \mathrm{m}$. They reported that Ra has a different effect on boiling heat transfer for different fluids. IN the case of water, the intermittent roughness displayed similar heat transfer coefficients, but the roughest surface showed the highest boiling performance. However, for a more wetting, e.g., FC-77, at reduced pressure, $\operatorname{Pr}=0.0064$, the heat transfer coefficient increased continually with increasing roughness. Geisler et al. [2] used electrical discharge machined surfaces in combination with microchannels and found an enhancement as compared to a polished surface, taking into account the effect of reduced pressure. They attributed low flux enhancement to Bond Number (ratio of gravitational to surface tension forces) and found that the enhancement is insensitive to channel aspect ratio. Vishal et al. [3] created square-pillar structures using wire EDM and found a 250\% enhancement in boiling heat transfer for water and $100 \%$ enhancement for isopropyl alcohol as compared to a polished surface. Although EDM has been used to produce surfaces with enhanced boiling heat transfer performance, however, no study reported the boiling enhancement in terms of EDM machining parameters. Since, it is possible to have different textures with the same surface roughness with EDM by using various combination of the machining parameters [4], this study is an attempted to address the effect of EDM machining parameters on boiling heat transfer enhancement. The work reported in this paper is related to the effect of one of the EDM machining parameters, which is pulse discharge duration on boiling heat transfer. Other machining parameters like pulse current, peak voltage have been kept constant. Boiling heat transfer coefficients were correlated with EDM pulse discharge duration. 


\section{Experimental Setup}

The experimental test rig shown in Figure 1 was used for the boiling experiments. It consists of a $20 \mathrm{~cm}$ diameter stainless steel vessel (13) to hold 4 litres of deionised water. A stainless-steel skirt (16) was affixed in the middle of the vessel to support the liquid. The bottom face of this skirt carries the test block assembly along with a heat insulation system (9). A $25.4 \mathrm{~mm}$ diameter and $71 \mathrm{~mm}$ length aluminium test block (17) was installed at the centre of the skirt. The test block has three $250 \mathrm{~W}$ cartridge heaters installed at the bottom, that were referred as main heaters (8) with Type E thermocouple installed along its length for determining the temperature profile.

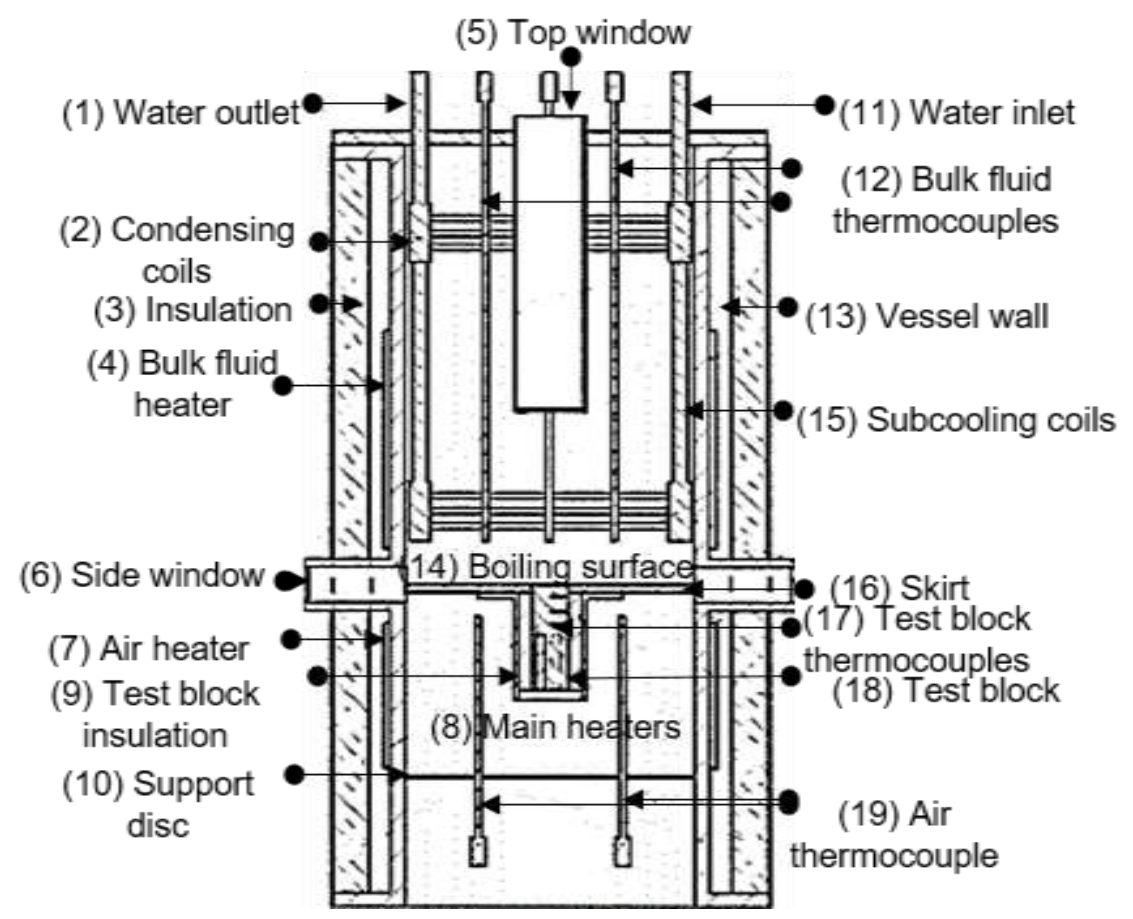

Fig. 1: Experimental setup for boiling.

Bulk fluid heater (4) was wrapped around the boiling vessel to maintain the temperature of bulk liquid at saturation temperature. Alongside, an air heater (7) was installed at the bottom part of the vessel to prevent any heat loss from the test block in radial direction and direct the heat flux only in axial direction. A support disc (10) prevented the mixing of air around test block with the air in the room. A linear best fit was carried out on the measured temperature profiles to calculate the wall heat flux (q") and surface temperature $\left(\mathrm{T}_{\mathrm{s}}\right)$ using the equation (1) and (2):

$$
\begin{gathered}
T_{s}=\frac{\sum T_{i} \sum x_{i}^{2}-\sum T_{i} x_{i} \sum x_{i}}{n \sum x_{i}^{2}-\left(\sum x_{i}\right)^{2}} \\
\mathrm{q}^{\prime \prime}=\mathrm{k} \cdot \frac{\sum x_{i} T_{i}+\sum x_{i} \sum T_{i}}{N \sum\left(x_{i}^{2}\right)-\left(\sum x_{i}\right)^{2}}
\end{gathered}
$$

Where $\mathrm{N}$ is the number of temperatures reading at a distance $\mathrm{x}$ from the surface, $\mathrm{k}$ is the thermal conductivity of Aluminium test block at average temperature. Bulk fluid heater and air heater were controlled via PID controller with thermocouples installed inside the bulk fluid and air around test block providing feedback signal. However, the main heaters were controlled manually in terms of percentage of electric input. A condensing coil (2) was used to prevent any 
fluid loss during the experiments and was also used as a subcooling coil to cool the bulk liquid at the end of the experiment. Two opposing glass side windows (6) were used to visualize the boiling phenomenon at $3000 \mathrm{fps}$ using FASTCAM high speed camera.

The surfaces were prepared using the EDM machine available at McMaster Manufacturing Research Institute (MMRI). The machining setup is as shown in Figure 2. A copper tool electrode was chosen for all the experiments and the test block material was chosen as Aluminium 6061.
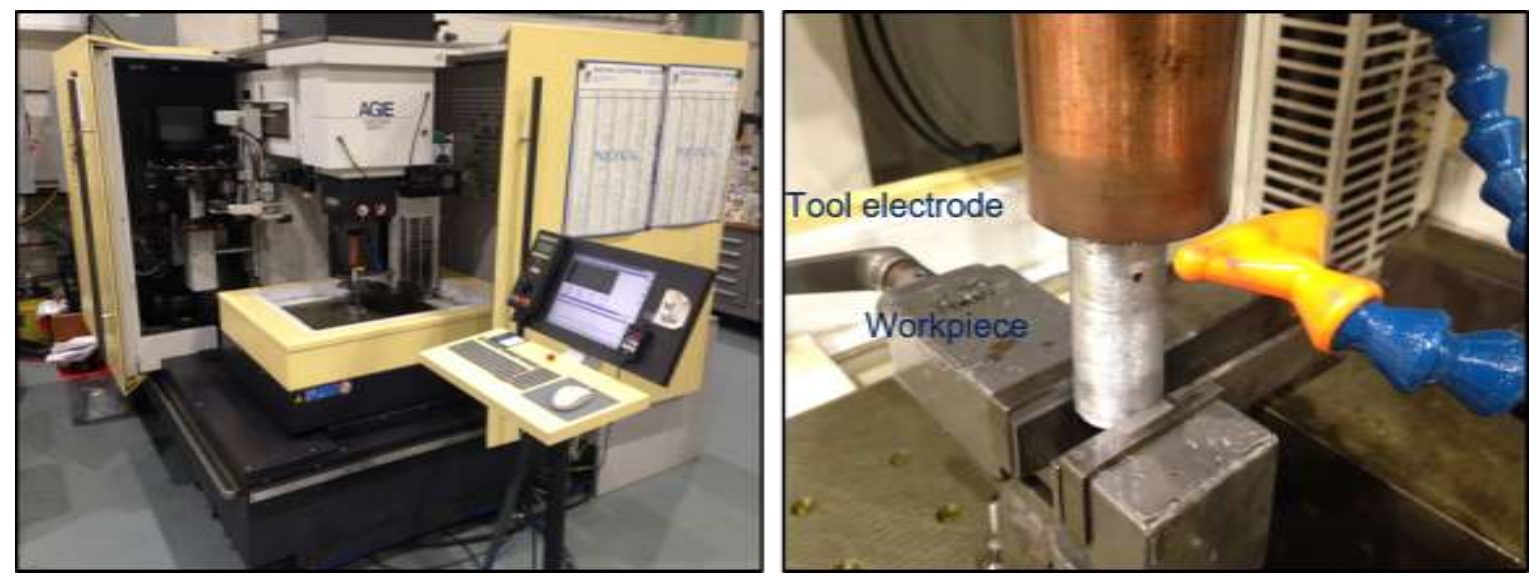

Fig. 2: Setup for Electrical discharge machining.

\section{Results and Discussion}

Experimental results for the boiling curves obtained by changing discharge duration from $65 \mu$ s to $1800 \mu$ s at a constant pulse current and peak voltage $\left(i_{\mathrm{e}}=39 \mathrm{~A}, \mathrm{U}=100 \mathrm{~V}\right)$ are shown in Figure 3. The boiling apparatus was accurate to a maximum error of $\pm 1.15^{\circ} \mathrm{C}$ at a wall superheat of $15^{\circ} \mathrm{C}$. Error bars associated with uncertainties at given wall superheats and heat fluxes are provided in the Figure 3. A polished surface prepared by polishing with emery paper $(R a=0.07 \mu \mathrm{m})$ was used a reference surface. Compared to such surface, the EDM textured surfaces showed enhancement in both the convective and boiling heat transfer regimes A $130 \%$ enhancement in the heat transfer coefficient was achieved by using the highest discharge duration (i.e., $\mathrm{t}_{\mathrm{e}}=1800 \mu \mathrm{s}$ ) at $\Delta \mathrm{T}_{\text {sat }}=11^{\circ} \mathrm{C}$. The heat transfer coefficients increase with increase in discharge duration from $65 \mu$ s to 1800 in both convective and nucleate boiling regimes. A lower Onset of Nucleate boiling (ONB) was observed with an increase in discharge duration. 


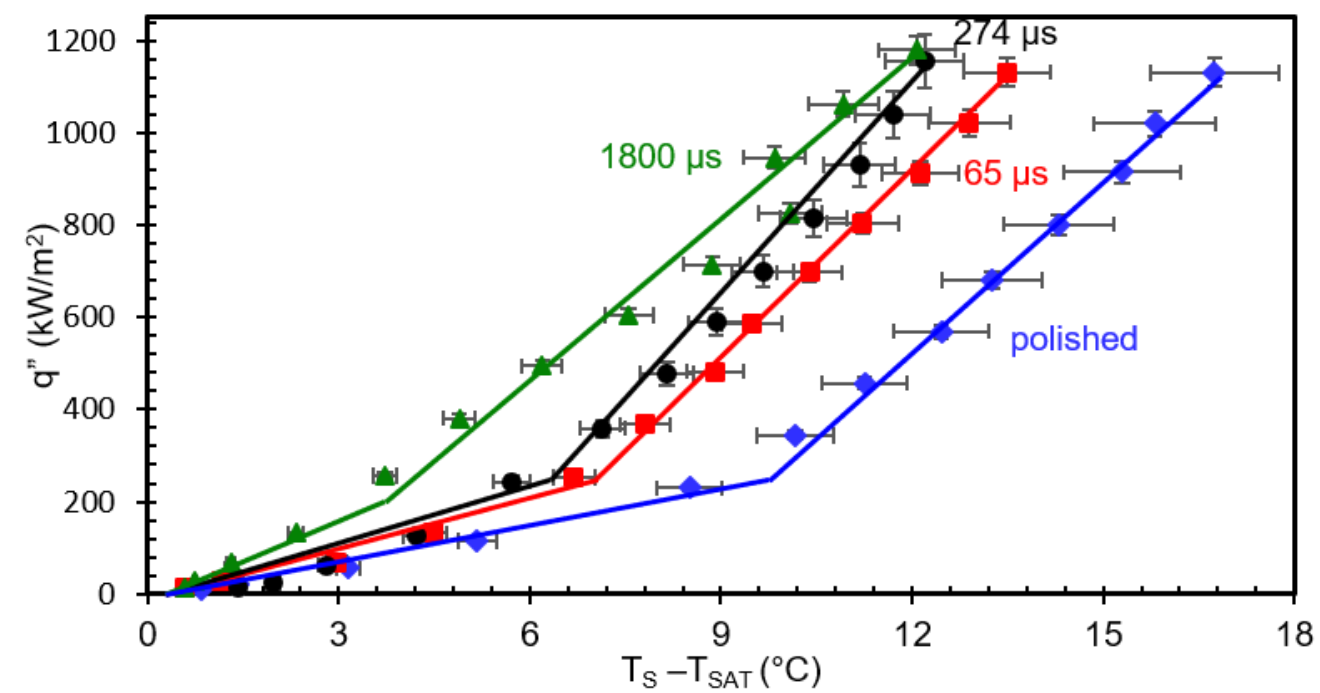

Fig. 3: Effect of EDM discharge duration (at $\mathrm{i}_{\mathrm{e}}=39 \mathrm{~A}$ ) on pool boiling heat transfer.

\section{Conclusion}

An experimental investigation of the effect of one of the EDM machining parameters on pool boiling enhancement has been carried out. EDM textured surfaces were manufactured by varying the discharge duration. Results show that discharge duration has a significant effect on heat transfer in the convective and nucleate boiling regimes as well as on the onset of nucleate boiling temperature (ONB). The heat transfer coefficients in convective and boiling regimes increased as a result of increase in discharge duration of EDM process. This suggests that there is a clear connection between the shape and size of craters formed from EDM process on the boiling heat transfer mechanism. A more detailed study will be carried out in future to see the effect of other machining parameters.

\section{Nomenclature}

$\mathrm{T}_{\mathrm{s}}$ : wall temperature

q": wall heat flux

$\mathrm{T}_{\text {sat: }}$ saturation temperature

$\mathrm{k}$ : thermal conductivity

$\mathrm{T}_{\mathrm{i}}$ : temperature of thermocouple at distance " $\mathrm{x}_{\mathrm{i}}$ " in the test block

$\mathrm{x}_{\mathrm{i}}$ : distance of thermocouple in the test block from the wall

\section{Acknowledgements}

The authors would like to acknowledge the financial support received from the Natural Sciences and Engineering Research Council of Canada (NSERC).

\section{References}

[1] B. J. Jones, J. P. McHale, and S. V. Garimella, "The Influence of Surface Roughness on Nucleate Pool Boiling Heat Transfer," J. Heat Transfer, vol. 131, no. 12, p. 121009, 2009.

[2] K. J. L. Geisler, A. Bar-Cohen, G. L. M. Hall, and C. Park, “HT2005-72666,” pp. 1-11.

[3] V. V. Nirgude and S. K. Sahu, "Enhancement of nucleate boiling heat transfer using structured surfaces," Chem. Eng. Process. Process Intensif., vol. 122, no. October, pp. 222-234.

[4] A. Klink, M. Holsten, and L. Hensgen, "Crater morphology evaluation of contemporary advanced EDM generator technology," CIRP Ann. - Manuf. Technol., vol. 66, no. 1, pp. 197-200, 2017. 